\title{
STUDY ON THE ANATOMICAL VARIATIONS AND MORPHOMETRY OF FORAMEN TRANSVERSARIA OF THE SUBAXIAL CERVICAL VERTEBRAE
}

\author{
M Yesender *1, P Devadas ${ }^{2}$, S Saritha ${ }^{3}$, B H Shiny Vinila ${ }^{4}$.
}

${ }^{* 1}$ Associate Professor, Department of Anatomy, Kamineni Academy of Medical Sciences and Research Centre, Hyderabad, Telangana, India

${ }^{2}$ Associate Professor, Department of Anatomy, Kamineni Institute of Medical Sciences, Narketpally, Telangana, India

${ }^{3}$ Professor, Department of Anatomy, Kamineni Academy of Medical sciences and Research Centre, Hyderabad, Telangana, India

${ }^{4}$ Senior Lecturer, Department of Anatomy, Panineeya Mahavidyalaya Institute of Dental Sciences and Research Centre, Hyderabad, Telangana, India

\section{ABSTRACT}

Introduction: The occurrence of vertebrobasilar insufficiency caused by rotation of the head has been reported due to thickened fibroligamentous structures, osteophyte formation, duplication of foramen transversarium, and congenital absence of the foramen transversarium. The size and variations of the foramen transversarium plays an important role in vertebrobasillar insufficiency. The present study was carried out on the anatomical variations of foramen transversarium.

Materials and Methods: The present study was carried out on 50 dry adult subaxial cervical vertebrae. Among that 40 were typical and 10 were seventh cervical vertebrae. All the foramen transversaria were observed for any anatomical variations and recorded. The anteroposterior and transverse diameters of all the foramen transversaria and the distance between the medial margins of uncinate process to the foramen transversarium were measured with the double tipped compass and the digital vernier calipers.

Results: The average transverse diameter of typical cervical vertebrae and seventh cervical vertebrae were 5.45 $\pm 0.84 \mathrm{~mm}$ and $5.13 \pm 1.22 \mathrm{~mm}$ respectively. The average anteroposterior diameters of typical and seventh cervical vertebrae were $4.84 \pm 0.69 \mathrm{~mm}$ and $3.91 \pm 1.17 \mathrm{~mm}$ respectively. The distance from medial border of uncinate process to foramen transversaria was $4.28 \pm 0.77 \mathrm{~mm}$ in typical and $5.44 \pm 1.28 \mathrm{~mm}$ in seventh cervical vertebare. The incidence of double bubble foramen in typical cervical vertebrae was reported as $17.5 \%$. The incidence of double foramen transversaria was $12.5 \%$ in seventh cervical vertebrae. Osteophytes were obstructing the foramen transversarium and narrowing it in $25 \%$ vertebrae.

Conclusion: The knowledge on the variations, dimensions and the distance between the medial borders of the uncinate process to foramen may be helpful for the neurosurgeons while performing decompression of artery through anterior approach to cervical spine.

KEY WORDS: Foramen transversarium, Cervical vertebrae, Vertebral artery, Osteophytes.

Address for Correspondence: Dr. M Yesender, Associate Professor, Department of Anatomy, Kamineni Academy of Medical sciences and Research Center, L B Nagar, Hyderabad, Telangana, India E-Mail: yesender.anat@gmail.com

\begin{tabular}{|c|c|c|}
\hline \multicolumn{3}{|c|}{ Access this Article online } \\
\hline \multirow{2}{*}{$\begin{array}{l}\text { Quick Response code } \\
\text { (1) }\end{array}$} & \multicolumn{2}{|c|}{$\begin{array}{l}\text { Web site: International Journal of Anatomy and Research } \\
\qquad \text { ISSN 2321-4287 } \\
\text { www.ijmhr.org/ijar.htm }\end{array}$} \\
\hline & $\begin{array}{l}\text { Received: } 13 \text { Feb } 2017 \\
\text { Peer Review: } 13 \text { Feb } 2017\end{array}$ & $\begin{array}{l}\text { Accepted: } 03 \text { Apr } 2017 \\
\text { Published (O): } 30 \text { Apr } 2017\end{array}$ \\
\hline DOI: $10.16965 /$ ijar.2017.151 & Revised: None & Published (P): 30 Apr 2017 \\
\hline
\end{tabular}




\section{INTRODUCTION}

The cervical vertebrae are identified by the presence of foramen transversarium (FT) in the transverse processes. Foramen transversarium is formed by the vestigial costal element fused to the body and the true transverse process of the vertebra [1]. The FT gives passage to the vertebral artery, vertebral veins, and sympathetic nerves from inferior cervical ganglion [2]. The embryogenesis of the vertebral artery begins at approximately 32 days of intrauterine life and is completed by 40 days, between the 12.5- and 16-mm stages [3,4]. Embryologically vertebral artery formation tales place by the fusion of the longitudinal anastomoses of cervical intersegmental arteries which were the branches of the primitive paired dorsal aorta. The intersegmental arteries gradually regress, except for the seventh intersegmental artery, which forms the proximal portion of the subclavian artery; including the point of origin of the vertebral artery [5].

The posterior circulation of the brain is completely depended on the basilar artery formed from the fusion of two vertebral arteries. The tortuous course of vertebral artery and rarely medial position of transverse foramen in relation to the joint of Luschka may result in lifethreatening iatrogenic injury following cervical decompression [6,7]. Previous studies reported on the variations in the number and size of the FT of the cervical vertebra which resulted in headache, migraine and fainting attack due to compression of vertebral artery [8]. The compression of the vertebral artery as a result of stenosis of the transverse foramen may also lead to clinically important consequences $[9,10]$. The present study is focused on the dimensions of the transverse foramen and the distance of the transverse foramen from the medial border of the uncinate process of subaxial cervical vertebrae in South Indian population and also elucidates the anatomical variation related to foramen transversarium which place the patients at risk.

\section{MATERIALS AND METHODS}

The present study was carried out on 50 dry human adult cervical vertebrae consisting of 100 foramen transversaria were collected from the department of Anatomy. Among that 40 were typical and 10 were seventh cervical vertebrae. Damaged vertebrae were excluded from the study. All the foramen transversaria were observed for any anatomical variations. Any the observed variations were recorded. The anteroposterior and transverse diameters of all the foramen transversaria were measured to determine the size of the foramen transversaria (Figure 1). The size of right and left sides were compared. The distance between medial margin of uncinate process to medial margin of foramen transversarium was also measured. All the measurements were taken with the double tipped compass and the digital vernier calipers.

Fig. 1: Typical cervical vertebra showing the measurements foramen transversarium. (A- Transverse diameter; B- Anteroposterior diameter; C - Distance between the medial margin of uncinate process to medial margin of foramen transversarium.)

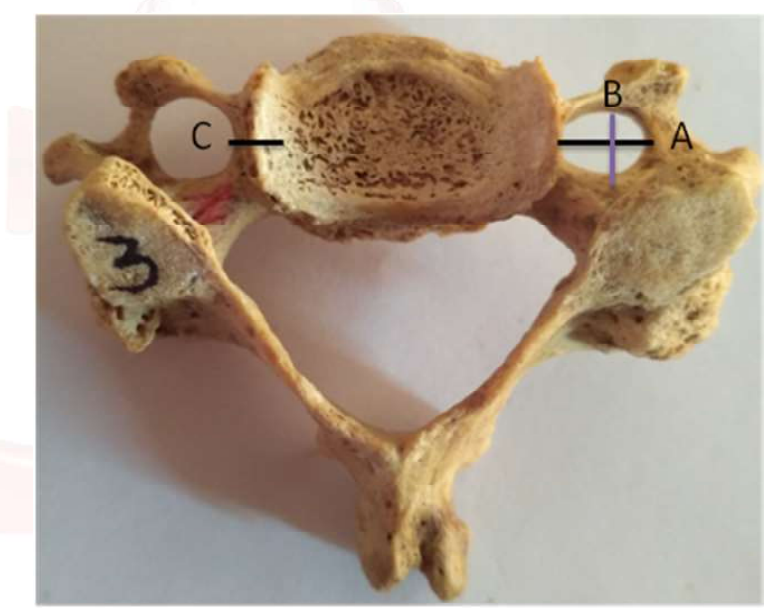

\section{RESULTS}

The size of the FT was determined by measuring transverse and anteroposterior diameters. The transverse diameter of typical cervical vertebrae was ranging from $3.79 \mathrm{~mm}$ to $7.38 \mathrm{~mm}$ and the anteroposterior diameter was ranging from $3.43 \mathrm{~mm}$ to $6.56 \mathrm{~mm}$. The average transverse diameter of typical cervical vertebrae and seventh cervical vertebrae were $5.45 \pm$ $0.84 \mathrm{~mm}$ and $5.13 \pm 1.22 \mathrm{~mm}$ respectively. The average anteroposterior diameters of typical and seventh cervical vertebrae were $4.84 \pm 0.69 \mathrm{~mm}$ and $3.91 \pm 1.17 \mathrm{~mm}$ respectively. The distance from medial border of uncinate process to foramen transversaria was $4.28 \pm 0.77 \mathrm{~mm}$ in typical and $5.44 \pm 1.28 \mathrm{~mm}$ in seventh cervical vertebrae. There was no significant difference between right and left sides. (Table 1, Figure 2). 
Table 1: Showing the mean and standard deviations of size of FT of typical cervical vertebrae and distance from medial margin of uncinate process to FT.

\begin{tabular}{|c|c|c|}
\hline Parameter (In milli meters) & Right side & Left side \\
\hline Transverse diameter of FT & $5.36 \pm 0.89$ & $5.53 \pm 0.80$ \\
\hline Anteroposterior diameter of FT & $4.88 \pm 0.70$ & $4.80 \pm 0.68$ \\
\hline $\begin{array}{c}\text { Distance between medial margin of } \\
\text { uncinate process to FT }\end{array}$ & $4.14 \pm 0.66$ & $4.42 \pm 0.84$ \\
\hline
\end{tabular}

The data was process for student's t test with which shows bilateral symmetry as the $P$ value was more than 0.05 for all parameters. Statistically significant difference was not found between right and left sides.

Fig. 2: Showing the bar diagram of size of FT of typical cervical vertebrae and distance from medial margin of uncinate process to $\mathrm{FT}$.

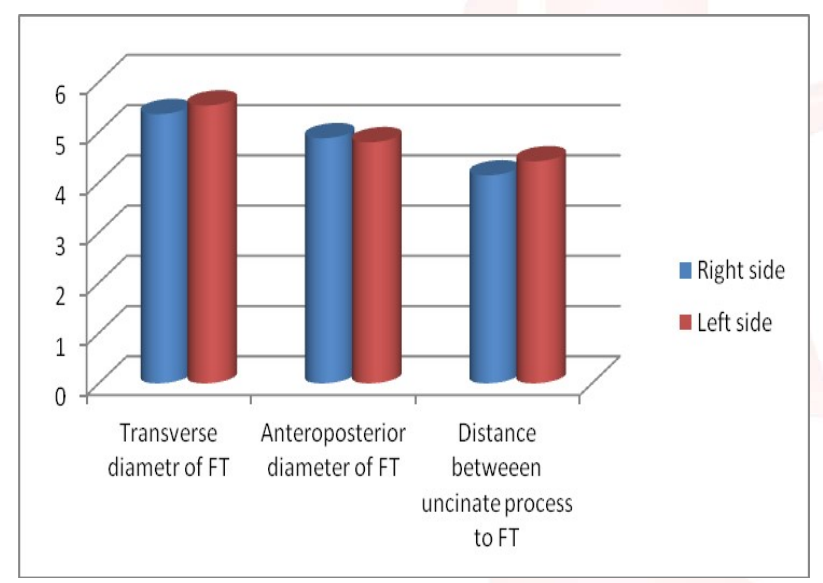

Table 2: Showing the mean and standard deviations of size of FT of seventh cervical vertebrae and distance from medial margin of uncinate process to FT.

\begin{tabular}{|c|c|c|}
\hline Parameter (In millimeters) & Right side & Left side \\
\hline Transverse diameter of FT & $5.20 \pm 1.10$ & $5.05 \pm 1.38$ \\
\hline Anteroposterior diameter of FT & $4.08 \pm 1.40$ & $3.75 \pm 094$ \\
\hline $\begin{array}{c}\text { Distance between medial margin of } \\
\text { uncinate process to FT }\end{array}$ & $5.22 \pm 1.04$ & $5.66 \pm 1.57$ \\
\hline
\end{tabular}

Double foramen transversaria was not seen in typical cervical vertebrae, but double bubble appearance (in complete double FT) was observed in 7 specimens out of 40 typical cervical vertebrae. In all the 7 specimens it was present unilaterally, 3 on left side and 4 on right side (Figure 3). Out of 10 seventh cervical vertebrae 3 were presented with double FT. In one specimen it was bilateral and in other two specimens unilateral (Figure 4, 5). Osteophytes were obstructing the FT and narrowing it in $25 \%$ of typical vertebrae. Total 10 typical cervical vertebrae were presented with osteophytes obstructing the FT out of 40 specimens (Figure 7).
Fig. 3: Typical cervical vertebra showing double bubble shape foramen transversarium.

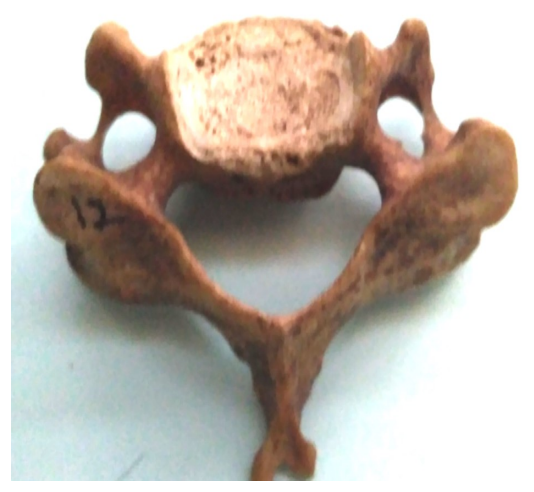

Fig. 4: Seventh cervical vertebra showing right unilateral double foramen transversarium.

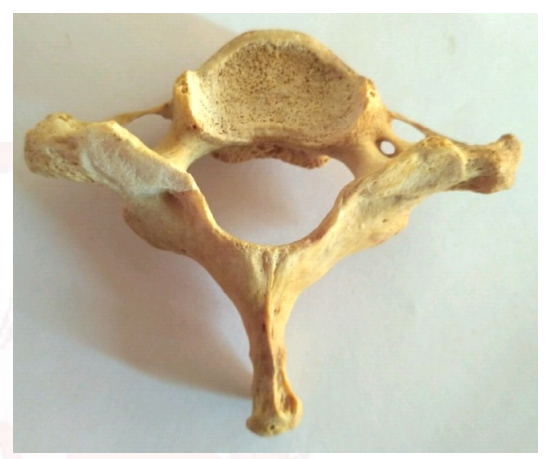

Fig. 5: Seventh cervical vertebra showing bilateral double foramen transversaria.

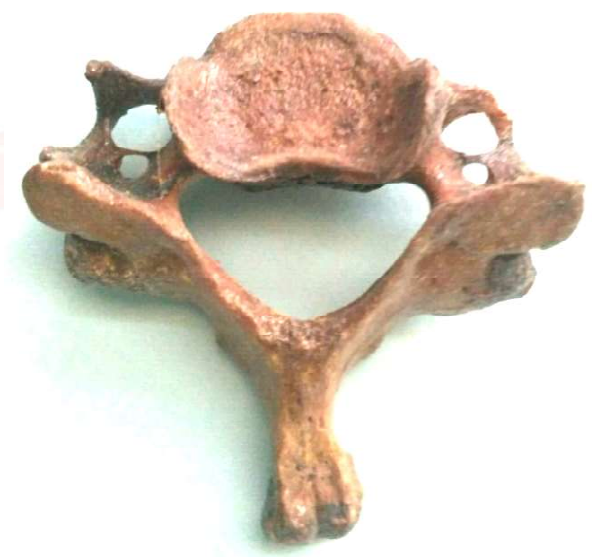

Fig. 6: Seventh cervical vertebra showing double bubble appearance of FT on left side and double FT on right side.

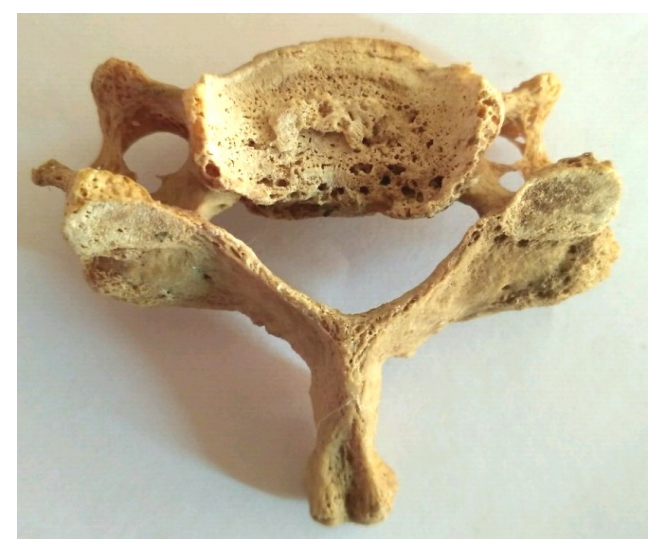


Fig. 7: Typical cervical vertebra showing the osteophyte obstructing the FT on right side and double bubble appearance of FT on left side.

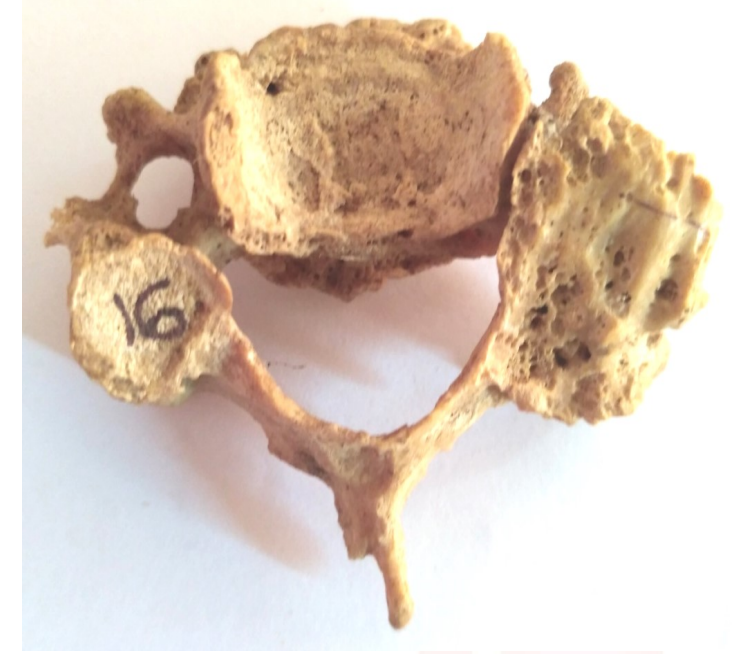

\section{DISCUSSION}

Stenosis or occlusion of the vertebral artery with head rotation leads to symptomatic vertebrobasillar insufficiency resulting in Bow hunter's stroke $[11,12]$. Head rotation produces stenosis or occlusion of a contralateral vertebral artery according to angiographic studies. The narrowing of the transverse foramen may predispose patients to vertebrobasilar insufficiency and thrombus formation especially with head rotation [13]. In the present study narrowing of foramen transversarium was observed either due to the presence of osteophytes or double bubble shape of foramen transversarium in typical cervical vertebrae. Osteophytes were observed in $25 \%$ specimens and double bubble was present in $17.5 \%$ of specimens. Presence of these variations further narrows the foramen transversarium and worsens the condition.

In the present study the transverse and anteroposterior diameters of foramen transversaria were ranging from $3.79 \mathrm{~mm}$ to $7.38 \mathrm{~mm}$ and the anteroposterior diameter was ranging from 3.43 $\mathrm{mm}$ to $6.56 \mathrm{~mm}$ respectively. The mean transverse diameter on right and lefts sides was $5.36 \pm 0.89 \mathrm{~mm}$ and $5.53 \pm 0.80 \mathrm{~mm}$ respectively; anteroposterior diameters on right and left sides were $4.88 \pm 0.79 \mathrm{~mm}$ and $4.80 \pm 0.68 \mathrm{~mm}$ respectively. Santosh Kaur Sangari et al., studied on American population and reported the mean transverse diameter on right and left sides as $5.69 \pm 1.04 \mathrm{~mm} \& 5.87 \pm 0.89 \mathrm{~mm}$ respectively; the anteroposterior diameters of right and left sides were $5.17 \pm 0.89 \mathrm{~mm}$ and $5.13 \pm 0.79 \mathrm{~mm}$ respectively. The dimensions of the Indian population show smaller foramen transversarium when compared to American population [13].

The mean distance from the medial margin of uncinate process to the medial margin og foramen transversarium was reported as $4.14 \pm 0.66$ on right side and $4.42 \pm 0.84 \mathrm{~mm}$ on left side which were smaller than the study by Santosh Kaur Sangari et al., where they reported it as $5.0 \pm 0.87 \mathrm{~mm}$ on right side and $5.0 \pm 1.0 \mathrm{~mm}$ on left side. The distance between the medial margin of uncinate process to medial margin of foramen transversarium plays important role while performing decompression of artery through anterior approach to cervical spine [13].

None of the typical cervical vertebrae showed double foramen transversarium. Double foramen transversaria were present only in seventh cervical vertebra and the incidence was reported as $20 \%$ which was similar with the previous studies by Apurba patra et al., and Chaudhari ML et al., but they also found double foramen transversaria in typical cervical vertebrae $[14,15]$.

\section{CONCLUSION}

Narrowing of foramen transversaria was observed in significant number of specimens due to the presence of osteophytes, which cause vertebral artery compression and injury. The knowledge on the variations, dimensions and the distance between the medial borders of the uncinate process to foramen may be helpful for the neurosurgeons while performing decompression of artery through anterior approach to cervical spine. The size of the foramen transversarium showed ethnic variation.

\section{Conflicts of Interests: None}

\section{REFERENCES}

[1]. William PL, Soames RW (ed) Axial skeleton Gray's Anatomy, 38th ed Churchill Livingstone, Philadelphia 1995:516.

[2]. Das S, Suri R, Kapur V. Double foramen transversaria. An osteological study with clinical implications. Int Med J 2005;12:311-3.

[3]. Sim E, Vaccaro AR, Berzlanovich A, et al. Fenestration of the extracranial vertebral artery: review of the literature. Spine 2001;26:139-42. 
[4]. Padget $\mathrm{DH}$. The development of cranial arteries in the human embryo. Contrib Embryol 1948;32:20761.

[5]. Loneta C, Omojola MF. Angiographic demonstration of bilateral duplication of extra cranial vertebral artery unusal course and review of literature Am J Neuroradiol. 2006;27:1304-1306.

[6]. L. J. Curylo, H. C. Mason, H. H. Bohlman, and J. U. Yoo. Tortuous course of the vertebral artery and anterior cervical decompression: a cadaveric and clinical case study. Spine. 2000;25(22):2860-2864.

[7]. B. R. Gantwerker,A.A. Baaj, P. H. Maughan, C. G. McDougall, and W. L. White. Vertebral artery injury during cervical discectomy and fusion in a patient with bilateral anomalous arteries in the disc space: case report. Neurosurgery. 2010;67(3):E874-E875.

[8]. Caovilla HH, Gananca MM, Munhoz MS, Silva ML: Sindrome cervical Quadros Clinicos Otoneurologicos Mais Comuns. Atheneu Sao Paulo. 2000; 3(11):95-100.

[9]. N. A. Ebraheim, J. Lu, J. A. Brown, A. Biyani, and R. A. Yeasting. Vulnerability of vertebral artery in anterolateral decompression for cervical spondylosis. Clinical Orthopaedics and Related Research. 1996;322:146-151.

[10]. S. W. Malik, B. D. Stemper, U. Metkar, N. Yoganandan, B. S. Shender, and R. D. Rao. Location of the transverse foramen in the subaxial cervical spine in a young asymptomatic population. Spine. 2010;35(12):E514-E519.
[11]. J. S. Citow and R. M. Macdonald. Posterior decompression of the vertebral artery narrowed by cervical stenosis. Surgical Neurology. 1999;51(5):495499.

[12]. T. Seki, K. Hida, M. Akino, and Y. Iwasaki. Anterior decompression of the atlantoaxial vertebral artery to treat bow hunter's stroke: technical case report. Neurosurgery.2001;49(6):1474-1476.

[13]. Santosh Kaur Sangari, Paul-Michel Dossous, Thomas Heineman, and Estomih Phillip Mtui. Dimensions and Anatomical Variants of the Foramen Transversarium of Typical Cervical Vertebrae. Anatomy research international. 2015;391823.

[14]. Apurba Patra, Harsimarjit Kaur, Usha Chhabra, Subhash Kaushal, Upasna Kumar. Double foramen transversarium in dried cervical vertebra: An osteological study with its clinical implications. Indian Journal of Oral Sciences. 2015;6(1):7-9.

[15]. Chaudhari ML, Maheria PB, Bachuwar SP. Double Foramen Transversarium in Cervical Vertebra: Morphology and Clinical importance. Indian Journal of Basic and Applied Medical Research. 2013; 8(2):1084-1088.

How to cite this article:

M Yesender, P Devadas, S Saritha, B H Shiny Vinila. STUDY ON THE ANATOMICAL VARIATIONS AND MORPHOMETRY OF FORAMEN TRANSVERSARIA OF THE SUBAXIAL CERVICAL VERTEBRAE. Int J Anat Res 2017;5(2.1):3708-3712. DOI: 10.16965/ijar.2017.151 